\title{
The Challenges of Musical Mediation through Streaming
}

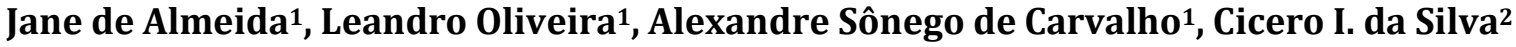 \\ ${ }^{1}$ Laboratory of Cinematic Arts (LabCine) and PPGEAHC, Mackenzie Presbyterian University, São Paulo, Brazil \\ ${ }^{2}$ Cultural Analytics Lab., Federal University of São Paulo (Unifesp), São Paulo, Brazil \\ Email: janedealmeida@post.harvard.edu, leaoliveira@me.com, alexandresonego.art@gmail.com, csilva@weber.ucsd.edu
}

How to cite this paper: de Almeida, J. Oliveira, L., de Carvalho, A. S., \& da Silva, C. I. (2018). The Challenges of Musical Mediation through Streaming. Creative Education, 9, 2898-2911.

https://doi.org/10.4236/ce.2018.916218

Received: November 19, 2018

Accepted: December 24, 2018

Published: December 27, 2018

Copyright (C) 2018 by authors and Scientific Research Publishing Inc. This work is licensed under the Creative Commons Attribution International License (CC BY 4.0).

http://creativecommons.org/licenses/by/4.0/

\begin{abstract}
This article explores a dataset collected by a Facebook live streaming of the "Falando de Música" program, the São Paulo State Symphony Orchestra pre-concert lecture venue. Based on qualitative and quantitative interviews (online and face-to-face) as much as Facebook's own measures, this paper aims at analyzing the impact on online viewers. Reflecting on the concept of "liveness" and its historical developments, it describes some effects on the public by using the platform and the content accessibility. This research is a "work in progress" investigation to produce a video streaming methodology for online music lectures with a single person.
\end{abstract}

\section{Keywords}

Streaming, Orchestra, Liveness, Mediation, Facebook Streaming, Classic Music

\section{Introduction}

"Falando de Música" ("Talking about Music") is an educational program that has been held since 2008 with the purpose of mediating the knowledge of classical music to the public of OSESP Foundation - São Paulo State Symphony Orchestra - symphonic concert series. Founded in 1954, OSESP is one of the most important orchestras in Latin America, with a program of more than one hundred annual concerts, and tours around Latin America, the United States, Europe and in capital cities in Brazil. Its concert hall, Sala São Paulo, was inaugurated in 1999 and seats 1450 people (Rohter, 1999). Since its restructuring in 1997, OSESP and Sala São Paulo have been praised for their excellence in magazines such as Gramophone (Gramophone, 2008; Halse, 2015), and newspapers such as The New York Times (Rohter, 1999), The Times (Fisher, 2012), The 
Guardian (Cox, 2015). According to Gramophone, for example, "the orchestra has undergone something of a transformation over the last 10 years." Its recordings are made by renowned record companies (BIS Records, 2018), and it features projects such as the complete recordings of Prokofiev's Symphonies, conducted by Marin Alsop, and also the complete Villa-Lobos Symphonies, conducted by Isaac Karabtchevsky.

"Falando de Música" is the orchestra official pre-concert lecture. It is offered one hour before each event, on Thursday, Friday and Saturday throughout the symphonic official season, which takes place from March to December. The lectures are delivered by the musicologist and conductor Leandro Oliveira. They rely on audio-visual devices and piano support, sometimes with the participation of guest artists participating in interviews.

The program was created due to public demand, since the audience felt encouraged by informal explanations given by orchestral conductors minutes before the concert, with musicians already onstage. These interventions, sporadic and spontaneous, discussed some musical compositions presented and elucidated connections relating the works of the evening. One methodological element that is considered important to "Falando de Música" is the style of the presentation; even though the process of researching sources on the authors and the pieces follows academic rigor, it is marked by informality and humor.

The scheduling of "Falando de Música" is established as forty minutes long, beginning one hour before the concert. This calendar considers the public reality of Sala São Paulo: Located in a degraded and violent area, the downtown of a metropolis with more than ten million inhabitants and very precarious urban transportation access. Also, it takes into account the time spent by the audience in moving from the classroom to the concert hall.

"Falando de Música" is currently publicized by being referenced in concert tickets and in publications of the orchestra, such as the website or the weekly and annual program books (Naxos Records, 2018). In 2017, the project presented 98 lectures, with the participation of 8837 people, reaching an average of 90.17 people per event (OSESP Foundation, 2017). In 2016, 92 lectures were held for a total attendance of 8609 people, reaching an average of 93.57 people per event (OSESP Foundation, 2016). This number represents just over $7 \%$ of the audience attending the concert at Sala São Paulo (Jusbrasil, 2008).

Increasing the audience and the access to classical music are two important issues for the OSESP Foundation. With the stated goal of "developing programs for the access to essays and didactic concerts to both students and teachers", OSESP's mission is “to support, encourage, assist, develop and promote culture, education and social assistance, with emphasis in music concerts, instrumental and vocals", as much as "to develop programs in order to encourage the formation of audiences of children and adults" (OSESP Foundation, 2018). These goals are directly justified by the consonance with the Brazilian law which made teaching music mandatory-a piece of legislation which does do not specify contents and aims at developing creativity, sensibility and social integration 
through contact with music and art (Brazilian Chamber of Deputies, 2008).

Based on data from previous public satisfaction surveys, Falando de Música presents positive results and public acceptance. Conducted by the marketing department of the orchestra, these pools were carried out intermittently between the years 2008 and 2012 and were aimed at validating some methodological and formal presentation assumptions, such as the use of the piano, the opportunity to employ technical vocabulary, among others. These are not going be to commented here.

In 2016, a research to evaluate the quality of "Falando de Música" pedagogical mediation was conducted by researcher Mirian Celeste Martins within the scope of the art-education field. Another research was recently conducted, using questions for the two audiences of "Falando de Música", the local and the streaming on the internet viewers. The present article does not focus on the comparison between the results of this last "field research" of "Falando de Música" (2018) with the previous one (2016). The article brings to mind some initial effects of the streaming of "Falando de Música" on social media, comparing the satisfaction indexes and the outreach of the audience in face to those available on their webcast. Since it is a "work in progress" research aiming to produce a video streaming methodology for online music lectures with a single person, the questions also intend to gain knowledge and understanding on online video streaming.

\section{Internet Streaming}

\subsection{Challenges and Dataset}

The aim of "Falando de Música" is to broaden the knowledge on concert music to the public of Sala São Paulo. One of Fundação Osesp (Osesp Foundation) supplementary objectives is to democratize the access to classical music (Ribas, 2015; Revista Concerto, 2009) and increase its audience-a challenge both for space limitations of concert halls and socioeconomic issues in a country where distributions of income is one of the worst on the planet and the level of education is low (Pires, 2018; Corrigan, 2015; OXFAM, 2017; Salata, 2016).

Streaming is a technology derived from the digital universe due to the composition of the computer and the internet connection, and has been developed relatively recently and incredibly grown due to the broadband connection (Stalbaum et al., 2018). The verb "to stream" was used to make sense of the use of point-to-point delivery of media (usually video and audio) between a provider and an end-user to whom were previously accustomed to the downloading system, in which it was necessary to have the whole file before being consumed (Topic, 2002). In the case of media delivered by streaming, data is received from the server and played with the help of a player or plugin that is part of the web browser and this allows live or prerecorded media to be played on-demand. The difference between "broadcast" and "streaming" is both contextual and technological. The idea of broadcasting is linked to the radio and television networks of the early and mid-twentieth century. With analogue transmission technologies, 
these networks have been and still are controlled by government institutions. Today broadcast technology is also basically digital, but its idea remains linked to media networks. One of the most striking differences from streaming to broadcasting, at least the one that derives from the networks, may be the interaction and engagement that the current platforms offer. In a streaming on Facebook, for example, viewers can post their comments that can be viewed live. It is possible for viewers to interact with the presenter and vice versa in a dual system of participation. Moreover, streaming technology is "still cheaper than broadcast equipment and comparable to printing equipment" and it has the power to spread educational content in a more democratic way (Topic, 2002: p. 192).

OSESP seems to be attentive to these facts and has broadcast its concerts since 2008 in HD via TV Cultura (the State of São Paulo television network) and, since 2011, via internet. With the possibility of the streaming, it was opened a new video channel for the Osesp orchestra, since the classic music listeners and the general audience can now be at home, at work or even commuting anywhere, anytime to be able to watch live a orchestra playing at Sala São Paulo from their own personal devices. However, over the course of these ten years, "Falando de Música" has never experimented any broadcast or streaming, even though, since the beginning, in 2008, several forms of remote interaction have been made possible by different technologies. Due to its low operating costs, it is surprising that no systematic transmission has ever been carried out through the available channels.

In advance, some questions are presented to the streaming project, such as: How these two different mediation scenarios-on-site and online-can impact public reception? What would be the positive and negative impacts of such forms of broadcasting? Broadly speaking, what contemporary models of "live" internet streaming can offer to a program like "Falando de Música"? Based on the relevance of the on-site project and its good evaluation in qualitative and quantitative terms, what could the impact of this transmission be in numerical terms and content enjoyment?

\subsection{Research Background}

Live streaming for performances, film and online classes has been one of the main subjects of the Laboratory of Cinematic Arts (LabCine:

http://www.labcine.com/), a research laboratory for cinematic arts located at Mackenzie Presbyterian University in São Paulo, Brazil. This research group explores and encourages the invention of artistic languages, methodological procedures and technical tools. One of its main partners is the CineGrid (http://www.cinegridbr.org/) research group, with which it has developed a series of experiments by streaming and experimenting with UHD contents for more than 15 years. In 2009 Labcine research group, along with CineGrid researchers, organized the first ultra-high definition images (4k) transmission over ultra-high speed networks (10 Gbps), streaming the feature film Enquanto a 
Noite Não Chega (2010, directed by Renato Falcão and Beto Souza)—linking São Paulo/Brazil to San Diego/USA and Keio/Japan (De Almeida, 2011). In 2010, LabCine produced and streamed a $4 \mathrm{~K}$ film from a soccer game (2014k) during the FIFA World Cup in Johannesburg - an exhibition developed especially for the venue. In 2011 the team produced a 4K 3D movie, "StereoEssays Rio de Janeiro" which was streamed during CineGrid, from University of California (San Diego) in real time to both Japan and Brazil. It was considered the first 4K 3D streaming in the world. After that, from 2012 to 2018, the research group produced more than 8 UHD films and countless experiments with ultra-high definition images streamed over photonic networks (De Almeida, 2016).

Since 2014 the group has started with live orchestras experiments. The group produced, for example, a demonstration that put together in the same place three musicians from the New World Symphony orchestra and the CineGrid Brazil audience at University of São Paulo (USP). The New World Symphony performed the soundtrack for the 1929 film São Paulo Sinfonia da Metrópole (São Paulo, a Metropolitan Symphony), by Adalberto Kemeny and Rodolpho Rex Lustig. The performers performed live at the New World Symphony in Miami, and their image was transmitted in $4 \mathrm{~K}$ along with a high definition audio system live to the Universidade de São Paulo Medical School Auditorium. The network bandwidth that this experiment required was something around 10 Gbps, and the connectivity between Miami and São Paulo was provided by AMPATH (Americas Path) and ANSP (Academic Network at São Paulo) academic networks.

Leandro Oliveira is specialized in orchestral live-broadcasting and streaming, and has been the director to multi-camera productions for more than one hundred concerts, to TV Cultura - São Paulo (Orquestra Sinfônica do Estado de São Paulo) and Symmetrica Inc. (Toronto Symphony Orchestra) (Figure 1), producing events with artists such as Marin Alsop, Yefim Bronfman, Vadim Gluzman, Osmo Vänskä, Claus Peter Flor, Helmuth Rilling, Louis Langrée, Yuja Wang, Sharon Bezaly, Thomas Dausgaard, Emmanuel Pahud, Maria João Pires, among others.

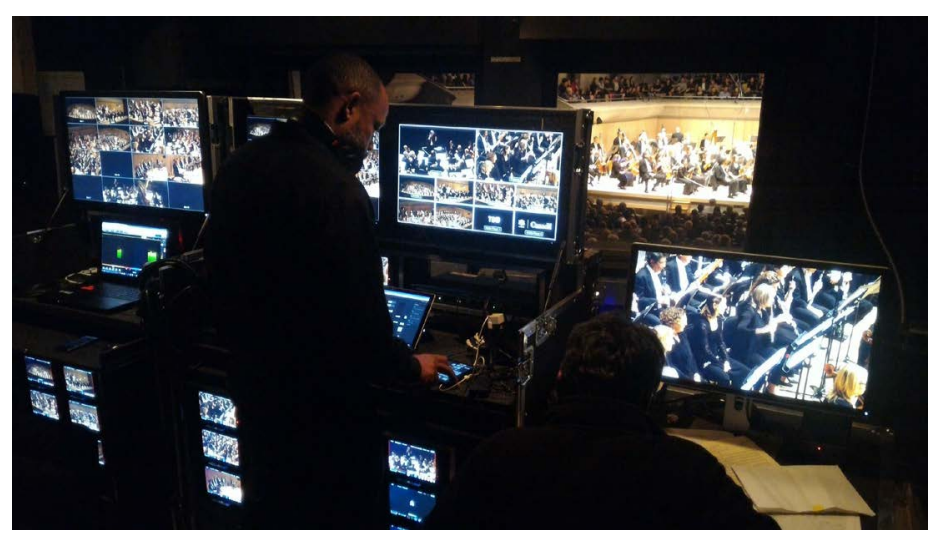

Figure 1. Leandro Oliveira (seated) coordinating a video streaming at the Roy Thomson Hall in Toronto, Canada (2017). Image: Cicero I. da Silva. 


\section{About Different Types of "Live"}

According to performance and broadcasting researcher Philip Auslander, there would be an update of the concept of "live" that acquires different connotations throughout the twentieth century. Due to the technological changes of the last decades, he argues that we end up recognizing in this "live" complex expedients that are, in themselves, different from what he calls "classic live". He also establishes the historical development of the concept of liveness in six perspectives (Auslander, 2008: p. 61). Below is a table in which the author summarizes the different types of live, their characteristics and cultural forms (Figure 2).

It is interesting to notice that from the initial perspective of his 1997 research, Auslander presents two new perspectives in this table that take into account internet streaming, both proposed and discussed by Couldry (Couldry, 2004, 2010), who suggests considering "two new forms of liveness" that do not involve television (online liveness via the Internet and "group liveness" via the mobile phone) (Couldry, 2004: p. 3). To these, Auslander also adds a sixth category: The "website goes live", which deals with the artificial media files (interactive media and chatterbots). In each of them, the concept of "live" expands its fundamental characteristics, so each level contains the precedent. I may also be considered important the fact that it is proper to streaming the "sense of connection" of mobile phones and the feedback between technology and the user, through interactive media and websites. Following the references of Nick Couldry, Auslander's table helps to think about the features of this kind of liveness and how internet streaming could be characterized in terms of live event.

The experiment of the present research deals with the premise that the new models of live are potentially important to compare the quality of the mediation in presence (live) and online situation, regarding the public of concert halls in general and the public of OSESP in particular, as well as to verify the impact of

\begin{tabular}{lll}
\hline Type of liveness & Significant characteristics & Cultural forms \\
\hline "Classic" liveness & $\begin{array}{l}\text { Physical co-presence of } \\
\text { performers and audience; } \\
\text { temporal simultaneity of } \\
\text { production and reception; } \\
\text { experience in the moment }\end{array}$ & $\begin{array}{l}\text { Theatre, concerts, } \\
\text { dance, sports, etc. }\end{array}$ \\
& $\begin{array}{l}\text { Temporal simultaneity of } \\
\text { production and reception; } \\
\text { experience of event as it } \\
\text { occurs }\end{array}$ & Radio, television, \\
& $\begin{array}{l}\text { Internet, etc. } \\
\text { Temporal gap between } \\
\text { production and reception; }\end{array}$ & LP, CD, film, \\
& $\begin{array}{l}\text { possibility of infinite } \\
\text { repetition }\end{array}$ & \\
Live recording & $\begin{array}{l}\text { Sense of co-presence } \\
\text { among users }\end{array}$ & Internet-based media \\
$\begin{array}{ll}\text { Internet liveness } \\
\text { (Couldry 2004) }\end{array}$ & $\begin{array}{l}\text { Sense of connection to } \\
\text { others }\end{array}$ & $\begin{array}{l}\text { Mobile phones, } \\
\text { instant messaging, etc. } \\
\text { Social liveness } \\
\text { (Couldry 2004) }\end{array}$ \\
$\begin{array}{l}\text { Feedback between } \\
\text { technology and user }\end{array}$ & $\begin{array}{l}\text { Websites, interactive } \\
\text { media, chatterbots, etc. }\end{array}$ \\
\hline
\end{tabular}

Figure 2. Historical development of the concept of liveness

(Auslander, 2008: p. 61). 
the live in conditions of streaming in the internet era, according to the typologies of the Auslander's table. That is, the comparison would be classified as a live broadcasting experiment by means of streaming, so a slight adaptation of the concept, which we should call "live streaming".

If for Auslander technology has entered all areas of liveness, almost eliminating the live nature of events (Auslander, 2008: p. 2), one can think of mixed events between on-site live (classical) and live technology already analyzed by him (Auslander, 2008: p. 26). One can also reflect on the potential of dissemination that the technological live would have to increase the on-site audience. This way, the technological live could suggest not the suppression of the presence, but the amplification of the public.

\section{Effects of Streaming: On-Site and Online}

As it has already been mentioned in the presentation, two researches were conducted on the public reception of the "Falando de Música" program: one in 2016, with the audience of the live lecture, which was conducted by field research on art mediation; and another one held in 2018 with live audience and also with the audience via internet streaming of the live lecture.

The 2016 survey was based on the qualitative method, in which "the data collected are considered qualitative, which means rich in descriptive details about people, places and conversations, and complex statistical treatment" (Bogdan \& Biklen, 1994: p. 16). These data are usually collected in a "natural context", without necessarily collecting, trying to prove hypothesis or measuring variables, seeking to apprehend the diverse perspectives of the subjects and the phenomena in their complexity. The qualitative approach is called naturalistic "[...] because the researcher attends the places where the phenomena in which he is interested naturally occur, focusing the data collected on the natural behaviors of the people" (Bogdan \& Biklen, 1994: p. 17) and in their interactions with the environment and the others, where they construct their repertoires of meaning. The research was carried out using a questionnaire of yes or no questions, and another one by scales in a gradual sequence of possible evaluations - Likert scale, with five degrees of verification. The questionnaire aimed to understand aspects such as project knowledge, the effect of the lesson, and the level of engagement and fidelity of the project.

From the analysis of the most immediate results of the research, the degree of satisfaction of the audience regarding the project should be emphasized, since the respondents claim to recommend the program and also understand that mediation is important for the enjoyment of the concert. The first conclusions of this part of the research should be raised in terms of hypothesis. It has been suggested three: 1) the project can be considered as a positive as a whole and well suited to its mission; 2) "Falando de Música" represents the direct portrait of the few opportunities for mediation that the public has with classical music in general; 3) to the extent of the variety and availability of idiosyncrasies, due to be- 
cause of the heterogeneity of the audience present, the class is being organized tailor-made for the interested public audience.

In this framework of possible conclusions, always in a hypothetical context, to be endorsed in other and future researches, it must be taken into consideration that perhaps the classes are well evaluated by the same opportunity of dialogue with an artistic modality considered hermetic, and in whose forums of mediation are scarce or very little accessed. In this sense, later questions, such as methodology, become secondary: the talk is very well received, due to the being welcomed by the opportunity offered by the forum, rather than by its intrinsic quality. After all, the result of the research concludes that the project has a loyal following and potential to increase its audience.

Regarding "Falando de Música", it can be intuitively predicted that internet streaming could produce this growth when considering that the audience will also include spectators absent from the physical event (Oliveira, 2001). However, it is difficult to measure in advance the quality and satisfaction of the reception, and this is a significant point to be investigated. Also, inferring on what kind of "cultural form" streaming would be framed, or even if it could be an addition to the Auslander table, setting up a particular type of mediation. "Falando de Múscia" live streaming is expected to guarantee a sense of co-presence between users and producers, even if limiting the online number of online users with the view of the speaker projection through a fixed camera and without the possibility to participate in the final question and answer session.

In 2018, parallel to live streaming, questionnaire forms were made available to the in site public, as well as with the audience through an internet streaming experiment placed at the same time using Google Docs. The objective was to measure the level of engagement and obtain qualitative data, increasing the database for analysis. For the analysis of the results, the concept of triangulation was used, in order to consider "different methodological approaches" (Flick, 2009: p. 61).

In the the on-site survey, at the beginning of the lecture, the public was invited to answer an one paper printed page form placed beforehand on their chairs with four questions:

1) After this lecture, do you feel better prepared to enjoy the concert?

2) Have you ever attended other Falando de Música lecture?

3) Would you attend this lesson if it were made available online?

4) Would you recommend the Falando de Música to someone?

On-site volunteers were anonymous. At the end of the conference, the surveys were deposited in a small box close to the exit door. It was collected 56 questionnaires based on a universe of 67 on-site attendants ( $83.58 \%$ engagement).

In the 56 questionnaires, people were invited to answer "yes" or "no" to the four questions. Regarding the answers, there are significant pieces of information, such as the sixteen people who commented that they have no interest in watching the event on Internet-what statistically represents $28 \%$ of total answers. To the question "Have you ever attended Falando de Música before?", 
there was $17.8 \%$ first time goers, as ten respondents saying they did not. One hundred percent of responses were positive (56 YES) regarding the question "do you feel better prepared to the concert". Likewise, all 56 participants (100\%) confirm that they would recommend "Falando de Música" to others. The numbers consolidate former information, collected both by Osesp's marketing pools (2008-2012) and professor Celeste Martins research (2016). They indicate the importance of the program, its high positive reviews as much as the good public engagement with the lecturer and his strategies to approaching musical subjects.

Live streaming was done over the course of the actual on-site lecture, mirroring the content that was broadcast, as usual, an hour before the concert. It was done in a simple manner, with a smartphone camera, positioned to the right of the stage, through the internet network of the concert hall itself, connected by the Facebook platform to the Laboratory of Cinematic Arts and Visualization (LabCine-http://www.labcine.com/). One day before the broadcasting, the platform counted with 103 followers (October 30, 2018). It is emphasized that the technical variables were sufficient for the experiment that needed a small capacity of processing of audio and video data. The streaming lasted 32 minutes and 6 seconds, corresponding to the full time of the lecture. According to the data provided by the Facebook platform itself, the transmission reached 3230 people and had 1061 views - of which 176 reacted spontaneously, that is, they made comments, shared or interacted via clicks, in the six gradations predicted by Facebook. The reactions can be organized as follows: 57 through sharing, 34 comments, 96 "like", 23 "love", 2 "haha", 3 "wow"; there were no "sad" or "angry" reactions.

Out of the 57 shares, only four were previously stimulated, all linked to Facebook webpages from project partners: the one from São Paulo State Symphony Orchestra, of the "O Estado de Arte" (O Estado de S. Paulo newspaper weblog), the "Falando de Música" and the lecturer's personal Facebook webpages. Out of 34 comments made during the streaming, 31 were made on the official project page, and most of them with positive acceptance signs ("like" signs and short words like "Hey!"). The lecture reached at its peak 40 people connected at the same time, with a total of 690 minutes of visualization. It is also relevant to mention that the average audience retention time, however, was only 16 seconds, and 384 people stayed connected to the video for more than 10 seconds, 1061 for at least 3 seconds.

The live streaming data allow us to assess the great outreach potential of the initiative with the proportion of 48 times the present public (3230 versus 67), more than 10 times the capacity of the classroom (250 people) and more than 2 times the capacity of the concert hall (1450 people). However, it is important to notice that the scope does not translate into attendance: less than half of the number of people caught watching the video (3230 versus 1061) and, of these, slightly more than a third (384 of 1061) endured the lesson for a minimum time. The fact that this high degree of approval does not translate into engagement could have different reasons, such as the limitations of the Facebook platform, 
the unedited lesson format with 32 minutes of continuous video, or even the broadcast time. These aspects can be verified later when, during the second phase of the research, a proposal will be made of building a methodology for streaming the lecture with the positioning of more than one camera through an experimental platform (Figure 3).

To complement the information and with the intention of evaluating some other qualitative parameter, in addition to those provoked by Facebook, a questionnaire with five questions was made available to viewers in a link into another platform, Google Docs. This action of the experiment elicited a small level of engagement, with only seventeen forms being answered, that is only $0.52 \%$ of the 3230 people audience who had access to the video or $1.60 \%$ of the 1061 who actually watched the video. The online questionnaire was composed with five questions, with "yes" or "no" option answers: 1) Have you watched this lecture in site?; 2) After lecture were you interested in coming to the concert?; 3) Would you watch a Falando de Música online show?; 4) Do you have access to musical concerts or classes that talk about music?; 5) Would you be interested in attending "Falando de Música" lectures without the concert? (Figure 4(a) and Figure 4(b)).

Although statistically they can be considered irrelevant, the few forms answered hint at the conclusion that the transmission had good public relative acceptance, in spite of the low adhesion of the integral lecture, with only two people who did not know of it in advance. All seventeen forms claim to be interested in attending the online lecture and going after to the concert; sixteen participants even claim to be interested in the talk independently from the concert, with thirteen claiming to have access to other similar programs.

\section{Conclusions}

The authors believe, based on the data collected by this research, that the live streaming on Facebook of the "Falando de Musica" venue can have a significant

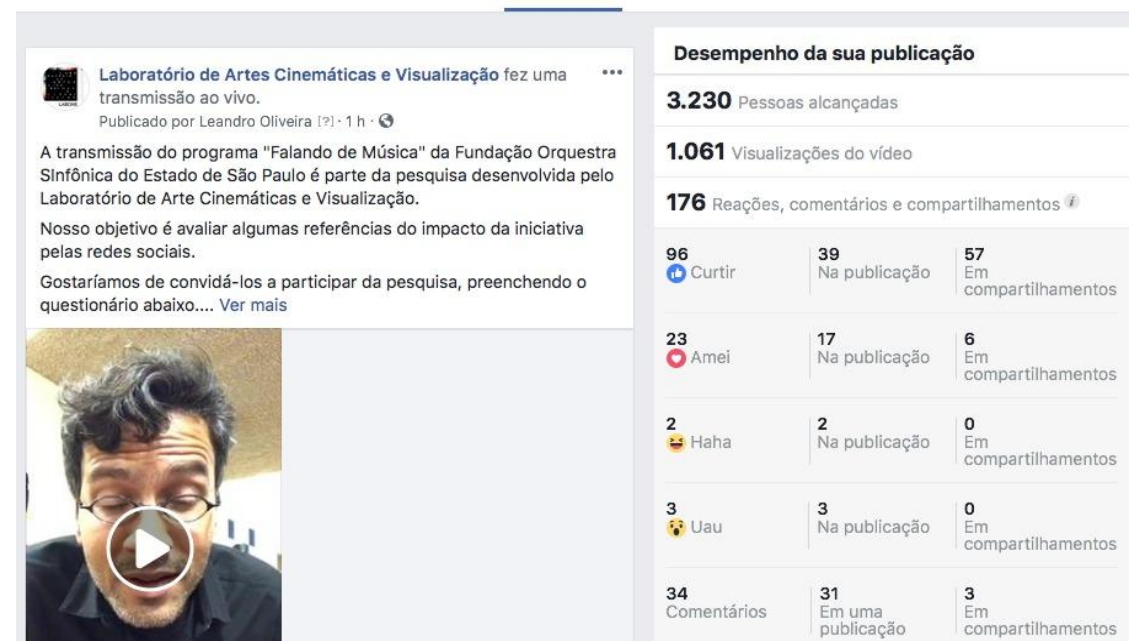

Figure 3. Facebook dashboard streaming system. 


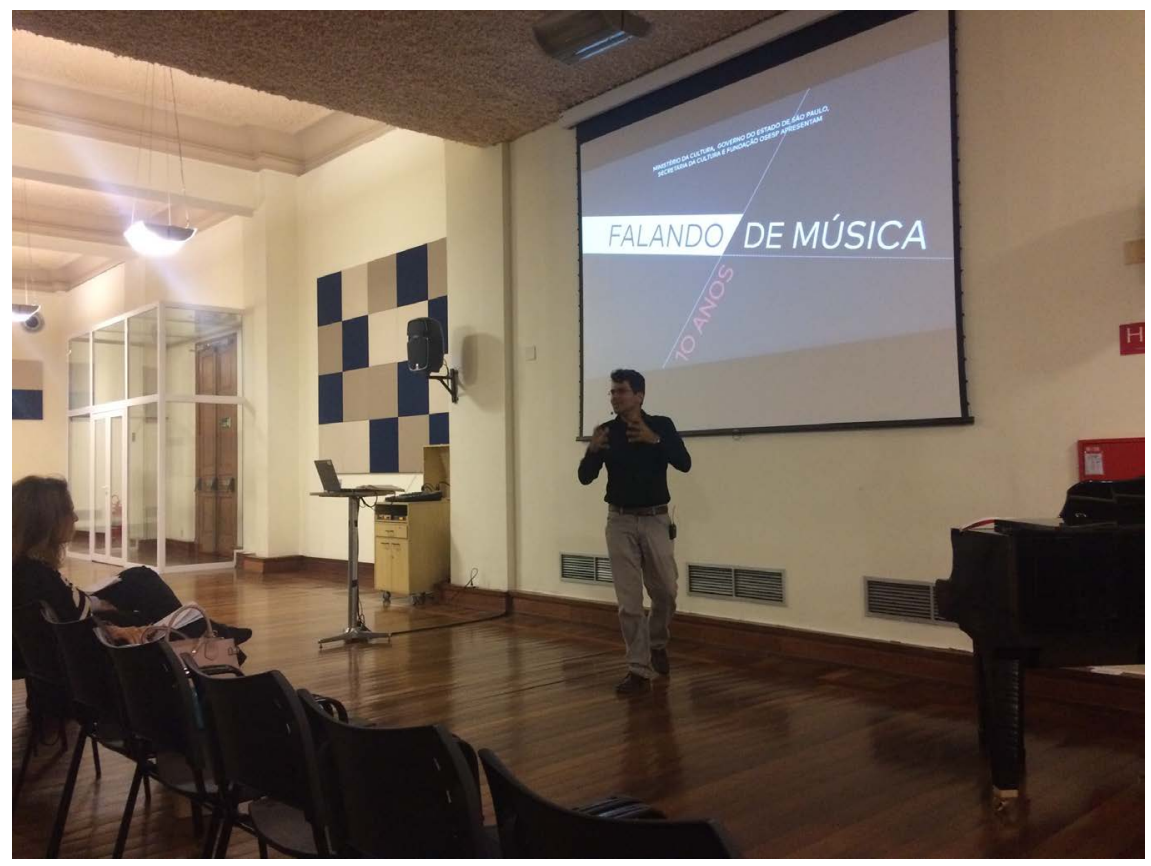

(a)

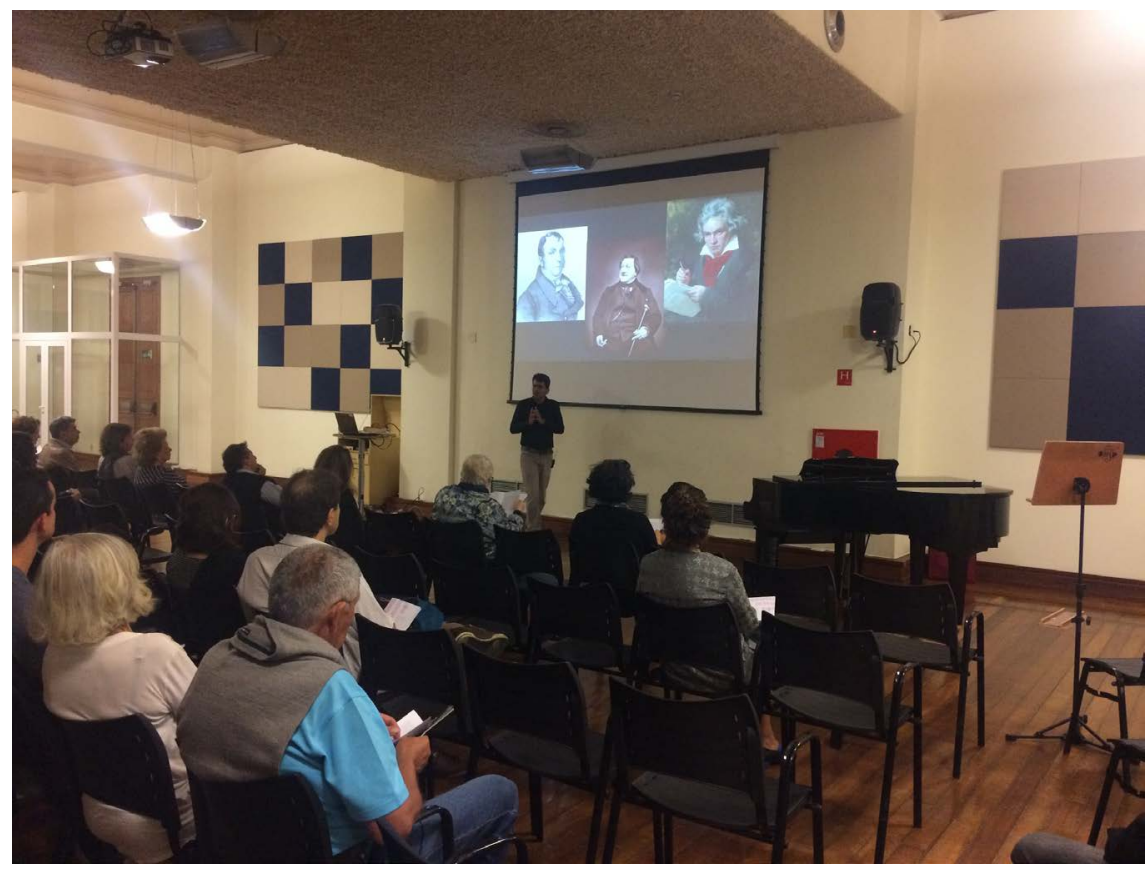

(b)

Figure 4. (a) and (b) Leandro Oliveira teaching at the Falando de Música venue at Sala São Paulo (2018). The streaming system is positioned at the right side of the room and the lecturer voice is captured by wireless mics and the sound output is done by two JBL speakers. Images: Cicero I. da Silva.

impact on the dissemination of the classical musical educational scenario in Brazil. The promising advertisement by live streaming on Facebook to "Falando de Musica" seemed significant. Despite the average time having fallen far short of the total of the lecture, with the interaction approach in five scales proposed by 
Facebook we should consider the streaming as positively evaluated. The reasons for those apparently paradoxical data are by now completely speculative. If the ephemerality of the contact does not damaged the public enjoyment, it could be allowed to conclude that the audience evaluated positively its own participation at the event, less than the pertinence of the content itself.

Although it has demonstrated potential audience reach, the broadcasting through social media networks of a classical music mediation project as "Falando de Música" lectures faces many challenges, the biggest of which is the full-time retention of a thirty-minute lecture. We shall suggest some strategies to deal with those challenges, as the exploration to new displays in visual-based contents, more interactive lecturer-camera activity, exploration of web-based engagement procedures such as the use of hyperlinks, quiz and so forth.

What is sure is that the transmission must take into consideration the nature of the platform itself-focused on short messages. The filmmaking grammar, with a fixed and distant camera, can also be a not so privileged solution for this media. There is an hypothesis, that should be taken into account, that the content itself, although apparently efficient for the model of classic live, is not very suitable for a live streaming, which needs more variety, editing or scenario. Those are matter for further researches, but it is stimulating to figure comparative results of one "straight" streaming, without any edition, and another, made with some kind of editing methodology. For an objective conclusion, any of these alternatives should also be investigated further.

As previously mentioned, this research is in progress and aims to lay the groundwork for an online transmission methodology to music educational lectures. For economy and portability reasons, the idea is that the speaker himself can be able to stream his classes, without the need to have ancillary devices. If it is understood that there is a need to have multi-cameras system to increase audience retention time, there is room for the development of applications for tablets and smartphones combining a basic script in order to predict camera movements.

\section{Acknowledgements}

We would like to thank the Mackpesquisa grant that made possible the publication of this article and the São Paulo State Symphony Orchestra (OSESP) for its kind agreement for this research. This work was also partially supported by The São Paulo Research Foundation (FAPESP grant 17/20434-6) under its BPE Program.

\section{Conflicts of Interest}

The authors declare no conflicts of interest regarding the publication of this paper.

\section{References}

Auslander, P. (2008). Liveness: Performance in a Mediatized Culture (2nd ed.). London, New York: Routledge. https://doi.org/10.4324/9780203938133 
BIS Records (2018). São Paulo Symphony Orchestra.

http://bis.se/orchestras-ensembles/sao-paulo-symphony-orchestra/

Bogdan, R. C., \& Biklen, S. K. (1994). Investigação qualitativa em educação. Trad.: M. J., Alvarez, S. B. Santos, \& T. M. Baptista (Eds.), Qualitative investigation in Education. Porto: Porto Press.

Brazilian Chamber of Deputies (2008). Lei 11769 de 18 agosto 2008. http://www2.camara.leg.br/legin/fed/lei/2008/lei-11769-18-agosto-2008-579455-public acaooriginal-102349-pl.html

Corrigan, G. (2015). Is Brazil Making Progress on Inequality? World Economic Forum. https://www.weforum.org/agenda/2015/09/is-brazil-making-progress-on-inequality/

Couldry, N. (2004). Liveness, "Reality", and the Mediated Habitus from Television to the Mobile Phone. Communication Review, 7, 353-361. https://www.tandfonline.com/doi/abs/10.1080/10714420490886952 https://doi.org/10.1080/10714420490886952

Couldry, N. (2010). Theorising Media as Practice. Social Semiotics, 14. https://doi.org/10.1080/1035033042000238295

Cox, T. (2015). Ten Worlds Best Concert Halls: Berlin, Boston, Tokyo. The Guardian. https://www.theguardian.com/travel/2015/mar/05/10-worlds-best-concert-halls-berlinboston-tokyo

De Almeida, J. et al. (2011). Tri-Continental Premiere of 4K Feature Movie via Network Streaming. FILE Future Generation Computer Systems, 27, 924-934.

De Almeida, J. et al. (2016). Sensemaking: A Proposal for a Real-Time on the Fly Video Streaming Platform. Creative Education, 7, 2515-2523. https://doi.org/10.4236/ce.2016.716238

Fisher, N. (2012). São Paulo State Symphony Orchestra debuts at the proms. The Times. https://www.thetimes.co.uk/article/sao-paulo-state-symphony-orchestra-debuts-at-theproms-5nwnvn2c3gs

Flick, U. (2009). Introdução à pesquisa qualitativa (3rd. ed.). Trad.: Costa, J. E. Porto Alegre: Artmed.

Gramophone (2008). The World's Greatest Orchestras. https://www.gramophone.co.uk/editorial/the-world\%E2\%80\%99s-greatest-orchestras

Halse, J. (2015) Gramophone Presents: Music, Art and Culture in Brazil. Gramophone. https://www.gramophone.co.uk/feature/gramophone-presents-music-art-and-culture-i $\underline{\text { n-brazil }}$

Jusbrasil (2008). TV Cultura estreia em alta definição com Concerto da OSESP ao vivo. https://governo-sp.jusbrasil.com.br/noticias/499890/tv-cultura-estreia-em-alta-definica o-com-concerto-da-osesp-ao-vivo

Naxos Records (2018). São Paulo Symphony Orchestra. https://www.naxos.com/person/Sao_Paulo_Symphony_Orchestra/46168.htm

New World Symphony at CineGrid Brasil 2014. https://www.youtube.com/watch?v=XYobbPsliQE

Oliveira, T. M. V. (2001). Escalas de mensuração de atitudes: Thurstone, Osgood, Stapel, Likert, Guttman, Alpert. FECAP, 2. https://www.fecap.br/adm_online/art22/tania.htm

OSESP Foundation (2016). Annual Report 2016 (in Portuguese). http://www.fundacao-osesp.art.br/upload/documentos/Transparencia/RelatorioAtivida desAnuais2016.pdf

OSESP Foundation (2017). Annual Report 2017 (in Portuguese). http://www.fundacao-osesp.art.br/upload/documentos/Transparencia/Relatorios-2017/ 
$\underline{\text { RelatorioAtividadeAnual2017_v2.pdf }}$

OSESP Foundation (2018). Social By-Law Change of the São Paulo State Orchestra Foundation.

http://www.fundacao-osesp.art.br/upload/documentos/Estatutos/Estatuto_Fundacao_ Osesp-4aAlteracao.pdf

Oxford Committee for Famine Relief (OXFAM) (2017). Brazil: Extreme Inequality in Numbers. https://www.oxfam.org/en/even-it-brazil/brazil-extreme-inequality-numbers

Pires, B. (2018). Brazil Flirts with a Return to the Dark Days. New York Times. https://www.nytimes.com/2018/08/24/opinion/brazil-flirts-with-a-return-to-the-darkdays.html

Revista Concerto (Concerto magazine) (2009). Osesp itinerante leva música clássica para o interior paulista (Osesp itinerant takes classical music to the interior of São Paulo). https://www.concerto.com.br/noticias/arquivo/osesp-itinerante-leva-musica-classica-p ara-o-interior-paulista

Ribas, D. (2015). Mapping Brazil - Cultural Participation: Access to Culture in São Paulo. DutchCulture.

https://dutchculture.nl/en/mapping/mapping-brazil-cultural-participation-access-cultu re-s\%C3\%A3o-paulo

Rohter, L. (1999). Arts Abroad; from Homeless to House-Proud: Brazil's “Other" Music. New York Times.

https://www.nytimes.com/1999/08/24/arts/arts-abroad-from-homeless-to-house-proud -brazil-s-other-music.html

Salata, A. (2016). Inequalities and the Brazilian new democracy: income distribution between classes in recent decades. Sociologia \& Antropologia, 6, 181-208.

https://doi.org/10.1590/2238-38752016v618

Stalbaum, B. et al. (2018). Mapping and Review of Audiovisual Editors and Streaming Platforms Based on Collaborative Technologies in Real Time. Anais Estendidos do Simpósio Brasileiro de Sistemas Multimídia e Web (WebMedia), S.l., 179-182.

Topic, M. (2002). Streaming Media Demystified (1st ed.). USA: McGraw-Hill Professional. 